\title{
ASPEK SANITASI DAN HYGIENE DI WARUNG MAKAN IKAN LAUT KAWASAN PANTAI LEBIH KABUPATEN GIANYAR
}

\author{
The Aspects of Sanitation and Hygiene in the Seafood Stalls at Lebih Beach
}

Areas in Gianyar District

I Wayan Agus Wijaya Adi Kesuma, Luh Putu Wrasiati*, Amna Hartiati

PS Teknologi Industri Pertanian, Fakultas Teknologi Pertanian, Universitas Udayana, Kampus Bukit Jimbaran, Badung, Kode pos : 80361; Telp/Fax : (0361) 701801.

Diterima 01 Oktober 2018 / Disetujui 4 Nopember 2018

\begin{abstract}
The aim of this study was to determine the level of knowledge of sanitation and hygiene aspects to food handlers and food stall owners in marine food stalls in Pantai Lebih area, Gianyar Regency. The method used is a non-probability type of saturated sampling. Questionnaires were distributed to the food handler and the measurement method used a dichotomy scale that had 2 answers, namely "Yes" and "No". Determination of the sample population was the entire restaurant located in the Pantai Lebih area and which was surveyed as food handlers. The type of research in Pantai Lebih food stall was descriptive which explained the state of sanitation and hygiene. The results of the study showed that in the marine fish food stalls in Pantai Lebih of Gianyar Regency Sanitation facilities for marine fish food stalls in Pantai Lebih, Gianyar Regency 93,75\% had fulfilled the requirements. In storing food ingredients, storing finished food, transporting food $100 \%$ food stalls already met hygiene requirements. The food service Food 97,5\% of food stalls had met hygiene requirements. Food processing $75 \%$ of food stall shad met hygiene requirements. Procurement of new food ingredients 56,25\% had met hygiene requirements.
\end{abstract}

Key words: sanitation, hygiene, seafood stall, Lebih.

\section{ABSTRAK}

Tujuan penelitian ini adalah untuk mengetahui gambaran tingkat pengetahuan aspek sanitasi dan hygiene kepada penjamah makanan dan juga pemilik warung makan di warung makan ikan laut kawasan Pantai Lebih, Kabupaten Gianyar. Metode yang digunakan adalah non-probability jenis sampling jenuh. Kuisioner dibagikan kepada food handler dan metode pengukuran menggunakan skala dikotonomi yang memiliki 2 jawaban yaitu "Ya" dan "Tidak". Penentuan populasi sampel yaitu seluruh rumah makan yang berada di kawasan Pantai Lebih dan yang disurvey penjamah makanan. Jenis penelitian di warung makan kawasan Pantai Lebih bersifat deskriptif yang menjelaskan keadaan sanitasi dan hygiene. Hasil penelitian menunjukkan bahwa di warung makan ikan laut kawasan Pantai Lebih Kabupaten Gianyar Fasilitas sanitasi warung makan ikan laut kawasan Pantai Lebih Kabupaten Gianyar 93,75\% sudah memenuhi syarat. Pada penyimpanan bahan makanan, penyimpanan makanan jadi, pengangkutan makanan 100\% warung makan sudah memenuhi syarat hygiene. Penyajian makanan 97,5\% warung makan sudah memenuhi syarat hygiene. pengolahan makanan $75 \%$ warung makan sudah memenuhi syarat hygiene. pengadaan bahan makanan baru $56,25 \%$ yang memenuhi syarat hygiene.

\footnotetext{
*Korespondensi Penulis:

Email:wrasiati@unud.ac.id
} 
Kata kunci : sanitasi, hygiene, warung makan ikan laut, Pantai Lebih.

\section{PENDAHULUAN}

Masalah kesehatan adalah suatu masalah yang sangat kompleks yang saling berkaitan dengan hal-hal lain seperti lingkungan, makanan dan gaya hidup. Makanan merupakan kebutuhan dasar manusia untuk melanjutkan kehidupan. Makanan yang dibutuhkan harus sehat dalam arti memiliki nilai gizi yang seimbangseperti : vitamin, mineral, hidrat arang, lemak dan lainnya. Makanan juga harus murni dan utuh dalam arti tidak mengandung bahan pencemar serta harus hygiene. Bila salah satu faktor tersebut terganggu makanan yang dihasilkan akan menimbulkan gangguan kesehatan dan penyakit bahkan keracunan makanan (Latudi, 2012).

Sanitasi dan hygiene merupakan suatu tindakan atau upaya untuk meningkatkan kebersihan dan kesehatan melalui pemeliharaan dini setiap individu dan faktor lingkungan yang mempengaruhinya, agar individu terhindar dari ancaman kuman penyebab penyakit. Prinsip-prinsip sanitasi dan hygiene makanan meliputi pemilihan bahan makanan, penyimpanan bahan makanan, pengolahan makanan, penyimpanan makanan, pengangkutan makanan, dan penyajian makanan (Depkes RI, 1994). Sanitasi makanan adalah salah satu usaha atau upaya pencegahan yang menitik beratkan kegiatan dan tindakan yang perlu untuk membebaskan makanan dan minuman dari segala bahaya yang dapat menggangu kesehatan, mulai dari sebelum makanan diproduksi, selama dalam proses pengolahan, penyimpanan, pengangkutan sampai pada saat dimana makanan dan minuman tersebut siap untuk dikonsumsi oleh masyarakat atau konsumen (Prabu, 2008). Hygiene adalah upaya kesehatan dengan cara memelihara dan melindungi kebersihan individu, misalnya mencuci tangan untuk kebersihan tangan, mencuci piring untuk melindungi kebersihan piring, membuang bagian makanan yang rusak untuk melindungi keutuhan makanan secara keseluruhan (Depkes RI, 2004).

Penelitian yang dilakukan oleh Isnawati (2012) di area warung makan Kelurahan Tembalang Kabupaten Semarang, menggunakan metode yang sama dapat menggambarkan kondisi penjamah dalam hal pengetahuan praktek sanitasi dan hygiene. Penelitian lain dilakukan oleh Isa (2012) pada rumah makan di kampus Universitas Negeri Gorontalo, menggunakan metode yang sama yaitu sampling jenuh yang menggambarkan prinsip pemilihan bahan makanan, penyimpanan bahan makanan, pengolahan makanan, penyimpanan makanan, pengangkutan makanan dan penyajian makanan. Hasil penelitian menunjukan bahwa prinsip pemilihan bahan makanan $83 \%$ rumah makan baik, prinsip penyimpanan bahan makanan 50\% rumah makan baik, prinsip pengolahan makanan $72 \%$ rumah makan tidak baik, prinsip penyimpanan makanan 50\% rumah makan baik, prinsip pengangkutan makanan $90 \%$ rumah makan baik, prinsip penyajian makanan $61 \%$ rumah makan baik. Oleh karena itu perlu dilakukan penelitian serupa di kawasan Pantai Lebih Kabupaten Gianyar supaya diketahui prinsip sanitasi dan hygiene di warung makan tersebut.

Tujuan dari penelitian ini adalah mengetahui aspek sanitasi dan hygiene warung makan ikan laut di kawasan Pantai Lebih Kabupaten Gianyar. Penelitian ini dilakukan survey sanitasi dan hygiene pada warung makan ikan laut di kawasan Pantai Lebih Kabupaten Gianyar.

\section{METODE PENELITIAN}

\section{Tempat dan Waktu Penelitian}

Penelitian ini dilaksanakan di warung 
makan ikan laut kawasan Pantai Lebih, Kabupaten Gianyar.Luas wilayah Desa Lebih $2.013 \mathrm{~km}^{2}$. Dasar pertimbangan pengambilan lokasi penelitian ini karena Desa Lebih merupakan kawasan pedagang yang saling bersaing tetapi belum tentu semua pedagang memahami tentang apa itu hygiene dan sanitasi. Waktu penelitian direncanakan pada bulan Februari 2018 - Maret 2018.

\section{Alat dan Bahan}

Alat yang digunakan dalam penelitian ini adalah kuisioner untuk para pedagang. Tidak ada bahan yang digunakan dalam penelitian ini, tapi warung-warung di kawasan Pantai Lebih menjadi sasaran untuk hygiene dan sanitasi. Rumah makan yang di survey adalah rumah makan yang menyediakan menu ikan laut berupa sate lilit, sop kepala ikan, ikan bakar, ikan goreng dan plecing kangkung. Terdapat 16 rumah makan dengan kategori seperti tersebut dan seluruh rumah makan akan di survey dengan memberikan kuisioner sebagai sampel penelitian.

\section{Penentuan Populasi dan Sampel}

Populasi yang diamati adalah seluruh rumah makan yang berada di kawasan Pantai Lebih, Gianyar. Yang disurvey datanya yaitu penjamah rumah makan yang berada di kawasan tersebut. Pengambilan data penelitian yang dilakukan yaitu semua rumah makan menjual makanan berbahan dasar ikan laut sebanyak 16 rumah makan digunakan sebagai sampel untuk dilakukan penyebaran kuesioner dan pengambilan data penelitian. Tahapan pelaksanaan penelitian dapat di lihat pada Gambar 1.

\section{Analisis Data}

Penelitian ini menggunakan kuantatif deskriptif untuk mencapai tujuan penelitian (Sutanto dan Kuntani, 2010). Metode pengumpulan data yang digunakan adalah jenis sampling jenuh. Kuisioner akan dibagikan kepada food handler dan metode dalam pengukuran ini menggunakan skala dikotomi yang hanya memiliki 2 jawaban yaitu, "Ya" dan "Tidak". Langkah awal yang dilakukan adalah melakukan uji validitas dan uji realibilitas. Uji validitas menggunakan total scored variable jika hasil r-hitung menunjukkan nilai yang lebih dari r-tabel maka pernyataan tersebut dinyatakan valid dan dapat digunakan untuk analisa selanjutnya. Dalam penelitian ini r-tabel adalah 0,361 , menggunakan signifikansi $5 \%$ dengan $\mathrm{n}=30$. Uji realibitasi dilakukan dengan koefisien $\alpha$ cronbach's. Apabila nilai cronbach's alpha >0,6 maka responden dinyatakan reliable.

\section{Uji Validitas}

Menurut (Zein, M. 2006) item pertanyaan pada kuisioner yang digunakan pada suatu penelitian harus valid. Untuk menentukan validitas item-item pada kuisioner, dilakukan uji validitas pada tiap item pertanyaan kuisioner. Statistik uji yang digunakan pada uji validitas adalah r-hitung. Nilai r-hitung akan dibandingkan dengan nilai r-tabel yang diperoleh dari tabel $r$ dengan derajat bebas sebesar n-2 dimana $n$ adalah jumlah responden yang digunakan. Pada penelitian ini jumlah responden yang digunakan adalah 30 sehingga derajat bebas pada tabel $\mathrm{r}$ adalah 28.

Nilai r-tabel untuk derajat bebas 28 adalah sebesar 0.361 Nilai r-hitung item yang lebih besar dari 0.361 dinyatakan valid. Angka tersebut menunjukkan bahwa setiap item pertanyaan dari masing - masing variabel pada kuisioner memiliki nilai r-hitung yang lebih besar dari pada $r$ tabel sebesar 0.361 sehingga 33 pertanyaan dalam kuisioner yang digunakan dinyatakan valid.

\section{Uji Reliabilitas}

Menurut (Ghozali, 2006) reliabilitas sebenarnya adalah alat untuk mengukur suatu kuesioner yang merupakan indikator dari variabel. Reliabilitas suatu pengukuran yang 
bertujuan untuk menunjukkan stabilitas dan konsistensi dari suatu instrumen yang mengukur suatu konsep dan berguna untuk mengakses kebaikan dari suatu pengukur. Reliabilitas berhubungan dengan konsistensi dari pengukur. Suatu pengukur dikatakan reliabel jika dapat dipercaya. Uji reabilitas dilakukan dengan metode internal consistency. Reliabilitas instrumen penelitian dalam penelitian ini diuji dengan menggunakan koefisien Cronbach's Alpha. Suatu variabel dikatakan reliabel jika nilai Cronbach's Alpha $>0,60$. Uji reliabilitas tersebut menyajikan nilai Cronbach's Alpha variabel pada kuisioner sebesar 0.899. Nilai Cronbach's Alpha yang dihasilkan lebih besar dari 0.6 sehingga dapat disimpulkan bahwa kuisioner yang digunakan sudah reliabel.

\section{HASIL DAN PEMBAHASAN}

Hasil penyebaran 16 kuisioner yang disebar ke semua warung makan yang berada di kawasan Pantai Lebih. Setelah melakukan pengolahan data dari 16 kuisioner, maka didapatkan rata-rata responden yang mengisi kuisioner berjenis kelamin perempuan sebesar 62,5\%, beralamat Banjar Lebih Beten Kelodan 100\%; berpendidikan SMA 50\%; SMP $18,75 \%$; SD $31,25 \%$, penghasilan perbulan 10 juta - 20 juta, harga per porsi mulai dari Rp. 15.000 - Rp. 17.000.

Berdasarkan data dan hasil observasi yang telah dilakukan pada warung makan ikan laut kawasan Pantai Lebih, Kabupaten Gianyar menunjukan bahwa sebagai berikut :

Tabel 1. Distribusi Warung Makan Ikan Laut Berdasarkan Indikator Penelitian

\begin{tabular}{rlrr}
\hline No. & \multicolumn{1}{c}{ Indikator } & Memenuhi Syarat (\%) & Tidak Memenuhi Syarat (\%) \\
\hline 1 & Pengadaan Bahan Makanan & 56.25 & 43.75 \\
2 & Penyimpanan Bahan Makanan & 100 & 0 \\
3 & Pengolahan Makanan & 75 & 25 \\
4 & Penyimpanan Makanan Jadi & 100 & 0 \\
5 & Pengangkutan Makanan & 100 & 0 \\
6 & Penyajian Makanan & 97.5 & 2.5 \\
7 & Fasilitas Sanitasi & 93.75 & 6.25 \\
\hline
\end{tabular}

Sumber Data Pribadi, 2018

\section{Pengadaan Bahan Makanan}

Dari hasil penyebaran kuisioner ke warung makan ikan laut di Pantai Lebih dari 16 responden yang menerima kuisioner pembelian bahan dasar seperti ikan laut ada di dua tempat : 9 orang pemilik warung membeli ikan laut langsung pada nelayan dan 7 orang pemilik warung membelinya di pasar atau di pengepul. Penyebaran kuisioner menunjukan bahwa warung mengetahui cara memilih bahan makanan yang segar pada ikan yaitu tidak busuk, tidak berlendir, daging tidak lembek, bebas dari bahan pengawet yaitu tekstur daging yang padat kenyal, bau segar seperti bau laut (amis), bagian dinding perut masih utuh, tidak hancur seperti bubur. Ciri-ciri sayuran yang segar yaitu warnanya hijau dan segar seperti baru dipetik, tidak layu atau berwarna kuning, daunnya sedikit robek dimakan ulat (bebas dari pestisida). Menurut (Nurmeilita, 2010) karakteristik ikan segar dapat dilihat dari mata yang menonjol, bau yang segar seperti bau laut, warna insang merah coklat sampai coklat kelabu dan tekstur padat, kenyal dan sulit menyobek kulit dari tulang belakang. Karakteristik sayuran segar(Rahma, 2013) dapat dilihat dari permukaan yang masih utuh, tidak layu, 
tidak busuk, terdapat gigitan ulat menandakan bebas dari pestisida, bebas dari tanah atau kotoran. Dari 16 responden yang menerima kuisioner, semua pemilik warung makan memakai bahan tambahan yang diijinkan seperti penyedap rasa dan bahan pewarna makanan. Menurut (Zuwita, 2016) daftar bahan tambahan yang diperbolehkan dan mendapat ijin dari POM sebagai berikut, (1) Pengawet ; asam benzoat, asam propionat, asam sorbat, natrium benzoat dan nisin. (2) Pewarna ; tartrasine. (3) Pemanis ; aspartam, sakarin dan siklamat. (4) Penyedap rasa dan aroma ; msg. (5) Antioksidan ; asam askorbat dan alfa tokoferol. (6) Pengemulsi, pemantap dan pengental ; lesitin, sodium laktat dan potassium laktat.

\section{Penyimpanan Bahan Makanan}

Menurut (Betty, 2000), ada beberapa cara penyimpanan bahan makanan yaitu dengan cara penyimpanan sejuk (cooling) dengan suhu $10^{\circ} \mathrm{C}-15^{\circ} \mathrm{C}$ untuk jenis minuman, buah dan sayur. Penyimpanan dingin (chilling) dengan suhu $4^{\circ} \mathrm{C}-10^{\circ} \mathrm{C}$ untuk makanan yang berprotein yang akan segera diolah kembali. Penyimpanan dingin sekali (freezing) dengan suhu $0^{0} \mathrm{C}-4^{0} \mathrm{C}$ untuk bahan makanan yang berprotein mudah rusak dalam jangka waktu 24 jam. Penyimpanan beku (frozen) yang suhu penyimpanan $<0^{0} \mathrm{C}$ untuk bahan makanan yang mudah rusak dalam jangka waktu > 24 jam.

Semua pemilik warung tahu cara penyimpanan makanan dalam kulkas yang sudah sesuai persyaratan jenis makanan. Penyimpanan bahan dasar (daging) dan sayur-sayuran disimpan dikulkas yang suhunya berbeda karena sayuran lebih cepat busuk dibandingkan daging. Untuk daging disimpan difreezer atau lemari pembeku sedangkan sayuran disimpan dilemari pendingin (kulkas). Hasil penyebaran kuisioner ke warung makan ikan laut menunjukan bahwa warung sudah mengikuti cara penyimpanan bahan dasar (daging) yaitu dengan ketebalan tidak lebih dari $10 \mathrm{~cm}$. Hal tersebut sangat mempengaruhi kualitas daging kalau daging disimpan terlalu tebal. Setiap bahan makanan yang diatur ketebalannya, maksudnya agar suhu dapat merata keseluruh bagian daging. Untuk penyimpanan bahan makanan, warung sudah mengikuti cara penyimpanan bahan makanan terpisah dengan tempat makanan jadi. Alasannya agar makanan yang sudah matang tidak menimbulkan bau dari daging mentah dan terbebas dari pencemaran. Hasil penyebaran kuisioner ke warung makan ikan laut menunjukan bahwa warung selalu membersihkan tempat penyimpanan makanan setiap pagi sebelum buka darung dan malam hari setelah warung tutup. Penyebaran kuisioner menunjukan bahwa warung tau cara penyimpanan bahan makanan yang disusun dalam rak-rak. Alasannya agar mudah waktu pengambilan bahan makanan dan bahan makanan tidak rusak.

\section{Pengolahan Makanan}

Pengolah makanan yang baik adalah pengolah yang mengikuti prinsip sanitasi dan hygiene. Menurut (Anwar, 1997) pengolah makanan menyangkut empat aspek, yaitu (1) Penjamah makanan harus mengetahui kebersihan panca indra, kebersihan kulit, kebersihan tangan, kebersihan dalam berpakaian dan kebersihan rambut. (2) Cara pengolahan makanan harus dilakukan dengan terlindung dan kontak langsung dengan tubuh. (3) Tempat pengolahan makanan harus memenuhin persyaratan kesehatan, yaitu lantai yang mudah dibersihkan, permukaan dinding rata dan mudah dibersihkan, atap atau langit-langit terbuat dari bahan kedap air dan tidak bocor. (4) Penerangan atau pencahayaan yang cukup untuk memudahkan dalam kebersihan.

Semua tenaga pengolah makanan selalu memakai alat bantu dalam pengambilan makanan jadi. Alat bantu yang dipakai sodet 
untuk mengambil ikan dari penggorengan, penjepit makanan untuk mengambil sayuran, sendok kuah. Penyebaran kuisioner ke warung makan ikan laut menunjukan bahwa dari 16 reponden yang menerima kuisioner ada 4 warung makan yang tenaga pengolahannya tidak memakai celemek, 12 warung makan tenaga pengolahannya memakai celemek dan sudah memenuhi standar hygiene. Penyebaran kuisioner ke warung makan ikan laut di Pantai Lebih dari 16 responden yang menerima kuisioner cuma 1 warung makan yang tenaga pengolahannya memakai tutup kepala. Sedangkan 15 warung makan lainnya belum memenuhin standar hygiene. Warung makan yang tenaga pengolahannya tidak memakai masker.Hal ini sudah tidak memenuhi standar hygiene.Alasannya kalau ada tenaga pengolahan yang sakit, makanan akan tercemar bakteri. Penyebaran kuisioner menunjukan bahwa, dari 16 responden yang menerima kuisioner Cuma 1 warung makan yang tenaga pengolahannya memakai sarung tangan saat mengolah makanan. Sedangkan 15 warung makan lainnya tidak memakai sarung tangan dan belum memenuhi standar hygiene. Untuk mengolah bahan makanan dengan bersih yaitu untuk mempersiapkan makanan yang berkuah, pastikan air kuah dimasak hingga mendidih dengan suhu $70^{\circ} \mathrm{C}$, mencuci bahan makanan dengan bersih, pisahkan bahan makanan yang mentah dengan bahan makanan lain, masak makanan sampai matang, panasakan kembali makanan kalau sudah dalam keadaan dingin.

\section{Penyimpanan Makanan Jadi}

Warung makan ikan laut di Pantai Lebih menyediakan tempat makanan yang sudah matang, yaitu nampan untuk tempat sate dan sayuran, termos nasi, panci untuk tempat kuah bakso ikan. Penyajian makanan menggunakan mangkok kramik, piring makan. Selain itu rumah makan sudah menyimpan makanan dengan tertutup menggunakan kain dan tudung saji makanan yang terbuat dari plastik agar mudah dibersihkan. Hal ini sudah memenuhi hygiene untuk waktu penyimpanan makanan kurang dari 6 jam. Kalau lebih dari 6 jam makanan yang matang masih tersisa akan dipanaskan kembali. Menurut (Nuri, 2016) suhu ruang $5^{0} \mathrm{C}-60^{0} \mathrm{C}$ merupakan zona berbahaya pertumbuhan mikroorganisme. Makanan matang yang disimpan di suhu ruang sebaiknya tidak disimpan lebih dari $5-6$ jam dan jika melebihi waktu tersebut, sebelum makanan dikonsumsi sebaiknya dipanaskan kembali hingga suhu mencapai $70^{\circ} \mathrm{C}$. Penyebaran kuisioner menunjukan bahwa warung makan sudah mengetahui tempat makanan dapat mempengaruhi kualitas dari makanan. Alasannya tempat penyimpanan makanan adalah salah satu kunci dari kebersihan makanan. Kalau penyimpanan makanan jadi diletakkan disamping makanan mentah, bau dari makanan mentah akan tercemar kemakanan jadi. Kalau diletakkan sembarangan akan tercemar dari bakteri.

\section{Pengangkutan Makanan}

Penyebaran kuisioner ke warung makan ikan laut menunjukan bahwa warung makan sudah menyediakan tempat jhusus untuk pengangkutan makanan yang sudah matang, yaitu nampan untuk tempat sate dan sayuran, termos nasi, panci untuk tempat kuah bakso ikan dll. Warung makan tersebut memiliki cara tutup yang baik dan mudah dibersihkan, yaitu dari bahan plastik seperti tudung saji makanan dan dari kain agar mudah dicuci. Dalam pengangkutan makanan yang digunakan tidak bertumpuk-tumpuk karena sangat rentan dengan kejadian misalnya pada saat menyajikan makanan ke pembeli kalau pengangkutan dengan bertumpuk-tumpuk makanan akan jatuh.

Menurut (Prabu, 2009) pengangkutan makanan jadi / siap saji adalah sebagai berikut, (1) Setiap makanan mempunyai wadah masing-masing. Isi makanan tidak 
terlampau penuh untuk mencegah tumpah. Wadah harus mempunyai tutup yang rapat dan tersedia lubang hawa (ventilasi) untuk makanan panas. Uap makanan harus dibiarkan terbuang agar tidak terjadi kondensasi. Air uap kondesasi merupakan media yang baik untuk pertmbuhan bakteri sehingga makanan menjadi basi. (2) Wadah yang dipergunakan harus utuh, kuat dan ukurannya memadai dengan makanan yang ditempatkan dan tidak berkarat atau bocor. (3) Pengangkutan untuk waktu yang lama harus diatur suhunya dalam keadaan tetap panas $60^{\circ} \mathrm{C}$ atau tetap dingin $4^{0} \mathrm{C}$. (4) Wadah selama perjalanan tidak dibuka sampai tempat penyajian. (5) Kedaraan pengangkut disediakan khusus dan tidak bercampur dengan keperluan mengangkut bahan lain.

\section{Penyajian makanan}

Penyebaran kuisioner ke warung makan ikan laut, dari 16 responden yang menerima kuisioner ada 15 warung makan yang sudah memenuhi standar hygiene yaitu menyajikan makanan dengan cara tertutup sedangkan 1 warung makan menjawab tidak karena langsung masak dan menyajikan makanan. Hasil penyebaran kuisioner ke warung makan ikan laut menunjukan bahwa warung makan sudah menempatkan makanan yang jadi ditempat yang bersih dan terhindar dari pencemaran. Warung makan ikan laut sudah membersihkan dan mengeringkan tempat makanan jadi sebelum menghidangkan makanan. Dari penyebaran kuisioner ke warung makan ikan laut, dari 16 responden yang menerima kuisioner ada 15 warung makan yang sudah memenuhi standar hygiene yaitu mengambil makanan jadi menggunakan alat bantu. Sedangkan 1 warung makan tidak menggunakan alat bantu, melainkan menggunakan tangan. Warung makan ini menyajikan makanan hangat dengan suhu kurang lebih $60^{\circ} \mathrm{C}$ yang diukur dengan thermometer.Ini membuktikan sudah memenuhi standar hygiene.

\section{Fasilitas Sanitasi}

Menurut (Menteri Kesehatan Republik Indonesia, 2003) persyaratan sanitasi rumah makan/restoran secara lengkap sebagai berikut : memiliki air yang bersih; Pembuangan air limbah harus baik, saluran terbuat dari bahan kedap air, tidak merupakan sumber pencemar, misalnya memakai saluran tertutup, septic tank dan riol. Saluran air limbah dari dapur harus dilengkapi perangkap lemak; Toilet tidak berhubungan langsung dengan dapur, ruang persiapan makanan, ruang tamu dan gudang makanan. Toilet untuk wanita terpisah dengan toilet untuk pria, begitu juga toilet pengunjung terpisah dengan toilet untuk tenaga kerja. Toilet dibersihkan dengan deterjen dan alat pengering seperti kain pel, tersedia cermin, tempat sampah, tempat abu rokok dan sabun. Lantai dibuat kedap air, tidak licin mudah dibersihkan; Tempat sampah dibuat dari bahan kedap air, tidak mudah berkarat, mempunyai tutup dan memakai kantong plastik khusus untuk sisa-sisa bahan makanan dan makanan jadi yang cepat membusuk; Peralatan pencegahan masuknya serangga dan tikus tempat penyimpanan air bersih harus tertutup sehingga dapat menahan masuknya tikus dan serangga termasuk juga nyamuk Aedes aegypti serta albopictus; Disediakan juga tempat pengumpul sampah sementara yang terlindung dari serangga dan hewan lain dan terletak di tempat yang mudah dijangkau oleh kendaraan pengangkut sampah.

Hasil penyebaran kuisioner ke warung makan ikan laut di Pantai Lebih semua warung makan menggunakan air yang bersumber dari PDAM dan semua warung makan menyediakan toilet. Ada 6 warung makan yang toiletnya berhubungan langsung dengan dapur. Itu sangat tidak baik karena tempat masak berhubungan langsung dengan toilet. Pada warung makan yang berada di Pantai Lebih semua warung makan menggunakan tempat sampah yang berbahan 
kedap air agar tidak menimbulkan bau dan melakukan pengangkutan sampah maksimal 24 jam. Biasanya tidak sampai 24 jam sampah sudah dibuang ke tempat penampungan sampah. Pembuangan limbah hasil pengolahannya kesaluran yang tertutup agar tidak menimbulkan bau dan tidak mengganggu konsumen saat makan dan warung makan ikan laut di Pantai Lebih semua warung makan memiliki saluran limbah yang lancar.

\section{KESIMPULAN DAN SARAN}

\section{Kesimpulan}

Berdasarkan penelitian yang telah dilakukan dapat disimpulkan bahwa kuisioner yang disebar di warung makan ikan laut kawasan Pantai Lebih Kabupaten Gianyar sudah dinyatakan valid. Pada fasilitas sanitasi warung makan ikan laut kawasan Pantai Lebih Kabupaten Gianyar sudah memenuhi syarat $93,75 \%$, untuk sisanya $6.25 \%$ berada pada warung makan yang memiliki toilet tetapi berhubungan langsung dengan dapur atau ruang makan. Pada hygiene warung makan ikan laut kawasan Pantai Lebih Kabupaten Gianyar, untuk pengadaan bahan makanan sudah memenuhi syarat sebesar 56,25\%, penyimpanan bahan makanan $100 \%$, pengolahan makanan $75 \%$, penyimpanan makanan jadi $100 \%$, pengangkutan makanan $100 \%$, dan penyajian makanan $97,5 \%$.

\section{Saran}

Berdasarka hasil penelitian ini dapat disaranakan bagi penjamah makanan agar lebih mengutamakan kebersihan panca indra, kebersihan kulit, kebersihan tangan, kebersihan dalam berpakaian dan kebersihan rambut. Ketika seorang penjamah dalam keadaan sakit dalam pengolahan makanan, agar tidak ada bakteri yang bercampur pada makanan yang akan diolah dan makanan yang akan dihidangkan.
Dapat disaranankan memuat beberapa toilet umum untuk menjaga kebersihan warung makan. Kebanyakan toilet yang letaknya berhubungan langsung dengan ruang pengolahan makanan.

\section{DAFTAR PUSTAKA}

Anwar, N; Amelia, S; dan Putri, P. 1997. Aspek - Aspek dalam Pengolahan Makanan yang Memenuhi Persyaratan Sanitasi dan Hygiene. Mutiara Sumber Widya. Jakarta.

Betty. 2000. Persyaratan Hygiene Tempat Penyimpanan Bahan Makanan Dengan Suhu Tertentu.Ilmu Pangan Universitas Indonesia Press, Jakarta.

Departemen Kesehatan R.I. 2004. Kumpulan Modul Kursus Higiene Sanitasi Makanan dan Minuman.Jakarta.

Depkes RI. 1994. Pedoman Pengelolaan dan Penyehatan Makanan Warung Sekolah. Jakarta.

Ghozali. 2006. Apliasi Analisis Multivariate dengan Progam SPSS. BPP UNDIP. Semarang.

Isa, Novryanti. 2012. Study Hygiene dan Sanitasi Pada Rumah Makan Di Wilayah Kampus Universitas Negeri Gorontalo. Jurusan Kesehatan Masyarakat, Gorontalo.

Isnawati. 2012. Hubungan Hygiene Sanitasi Keberadaan Bakteri Coliform Dalam Es Jeruk di Warung Makan Kelurahan Tembalang. Fakultas Kesehatan Masyarakat Universitas Diponerogo, Semarang.

Latudi, Ratni. 2012. Aspek Hygiene dan Sanitasi Makanan di Pasar Jajan Kota Gorontalo.Universitas Gorontalo, Gorontalo.

Menteri Kesehatan Republik Indinesia. 2003. Persyaratan Sanitasi Rumah 
Makan/Restoran Lengkap. Jakarta.

Nuri, Astuti. 2016.Batas Maksimum Penyimpanan Makanan di Suhu Ruang. Fakultas Teknologi Pangan, IPB. Bogor.

Nurmeilita. 2010. Penilaian Mutu Organoleptik Ikan Segar dengan Ukuran yang Berbeda Selama Penyimpanan Dingin.Fakultas Perukanan dan Ilmu Kelautan, Manado.

Prabu. 2008. Hygiene dan Sanitasi Makanan. Fakultas Kesehatan Masyarakat Universitas Indonesia, Jakarta.

Prabu. 2009. Penyimpanan dan Pengangkutan Makanan (Prinsip Food Hygiene). Fakultas Kesehatan Masyarakat Universitas Indonesia, Jakarta.

Rahma. 2013. Hubungan Karakteristik dan Pengetahuan Tentang LIngkungan Sehat dengan Keputusan Konsumen dalam Membeli Sayuran Organik di Carrefour Flaza Medan Fair. Program sarjana Fakultas Kesehatan Masyarakat Universiras Sumatra Utara.Sumatra Utara.

Sutanto dan Kuntani.2010. Analisa Sanitasi dan Hygiene Penyajian Makanan di Kantin Universitas Kristen Petra Surabaya.Fakultas Ekonomi, Surabaya.

Zein, M. 2016. Pengaruh Part Isipasi Penyusunan Anggaran dan Kejelasan Sasaran Anggaran Terhadap Kinerja Aparat Pemerintah Daerah Kabupaten Siak dengan Komitmen Organisasi Sebagai Variabel Moderating. Fakultas Ekonomi Universitas Riau. Pekanbaru.

Zuwita, E. 2016.Daftar Bahan Tambahan Makanan yang Aman dan Dilarang Untuk Dikonsumsi. Jakarta. 